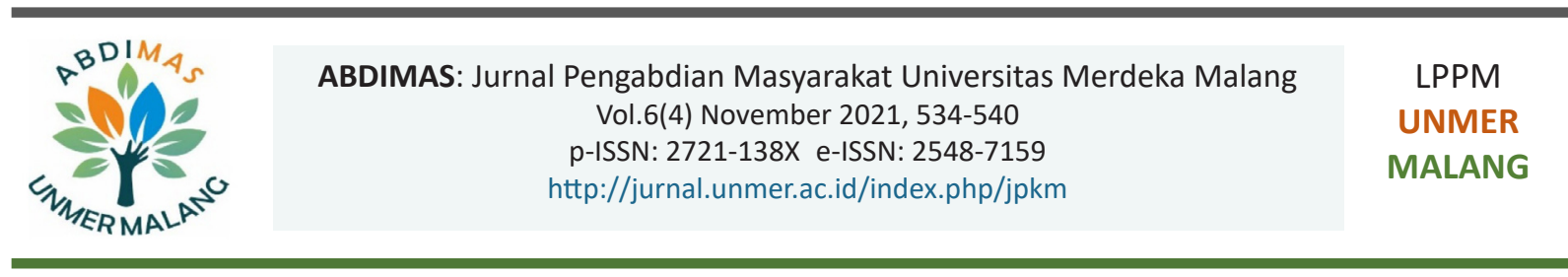

\title{
School garden as a learning alternative in the era of COVID-19 pandemic
}

\section{School garden sebagai alternatif pembelajaran di era pandemi COVID-19}

\author{
Okti Purwaningsih¹, Puguh Bintang Pamungkas¹, Triwahana Triwahana² \\ 'Departemen Agroteknologi, Fakultas Pertanian, ²Departemen Pendidikan Sejarah, Fakultas Kependidikan dan Ilmu \\ Pendidikan, Universitas PGRI Yogyakarta \\ Jl. PGRI I Sonosewu No.117, Yogyakarta, 55182, Indonesia
}

\section{ARTICLE INFO}

Received: 2021-02-23

Revised: 2021-04-24

Accepted: 2021-06-14

Keywords:

COVID-19, Online learning, Pandemic, School Garden

\section{ABSTRACT}

Indonesia as an agrarian country faces several obstacles to achieving food sovereignty, due to the limited number of the younger generation involved in the agricultural sector. Most of the farmers are elderly with limited capacity. Therefore, as early as possible, it is necessary to make efforts to increase interest in farming among elementary school students through School Garden activities. The introduction of the School Garden becomes an interesting lesson because students can carry out farming activities independently. This community service program was carried out at SD Model located in Ngemplak Sleman, Yogyakarta. This program aims to introduce the School Garden through urban farming so that it can foster interest in agriculture. The methods used include presentations with video tutorials and giving farming modules. The results of the implementation of the community service program showed that $97.7 \%$ of students liked the introduction of the School Garden activity and $81.4 \%$ of students felt that these activities foster their interest in agriculture.
\end{abstract}

(C)2021 Published by University of Merdeka Malang. This is an open access article distributed under the CC BY-SA 4.0 license (https://creativecommons.org/licenses/by-sa/4.0/)

How to cite: Purwaningsih, O., Pamungkas, P. B., \& Triwahana, T. (2021). School garden as a learning alternative in the era of COVID-19 pandemic. Abdimas: Jurnal Pengabdian Masyarakat Universitas Merdeka Malang, 6(4), 534-540. https://doi.org/10.26905/abdimas.v6i4.5512

\section{PENDAHULUAN}

Indonesia merupakan negara agraris dengan potensi sumber daya alam yang sangat melimpah. Sebutan 'gemah ripah loh jinawi' sangat sesuai untuk kondisi alam Indonesia, sehingga muncul syair lagu 'tombak kayu dan batu jadi tanaman' untuk menggambarkan betapa suburnya Indonesia. Namun, sangat disayangkan Indonesia masih harus mengimpor beberapa komoditas pangan untuk memenuhi kebutuhan masyarakat. Hal ini dikarenakan produksi dalam negeri tidak dapat mencukupi kebutuhan masyarakat. Pada tahun 2018 impor kedelai mencapai 2,5 juta ton; gula 101 ribu ton; tembakau 121,3 ribu ton; buah-buahan 1,5 juta ton; sayuran 904,8 ribu ton; dan beras 2,2 juta ton (BPS, 2019). Salah satu faktor penyebab rendahnya produksi pertanian karena terbatasnya sumber daya manusia di bidang 
pertanian. Orang-orang yang bergerak di bidang pertanian kebanyakan adalah para petani yang sudah lanjut usia sehingga ada keterbatasan tenaga, keterampilan, dan pengetahuan. Para generasi muda kurang tertarik untuk terjun di sektor pertanian karena mereka beranggapan sektor pertanian identik dengan 'kotor' karena bergelut dengan tanah dan pupuk serta hasil usaha tani kurang menjanjikan. Secara umum di tingkat nasional, partisipasi generasi muda di sektor pertanian mengalami penurunan. Faktor pendorong terjadinya pergeseran animo generasi muda dari sektor pertanian ke sektor non pertanian adalah gaji yang dijanjikan oleh sektor non pertanian lebih besar, image negative tentang pertanian, sempitnya kepemilikan lahan pertanian, kemudahan aksesbilitas pedesaan (Nugroho et al., 2018). Keterbatasan sumber daya manusia yang bergerak di sektor pertanian merupakan salah satu pembatas pengelolaan usaha tani secara optimal, ada kecenderungan rendahnya masukan teknologi dalam usaha tani, dengan kata lain usaha tani masih dikelola secara tradisional. Oleh karena itu, perlu dilakukan upaya untuk meningkatkan rasa kecintaan generasi muda terhadap pertanian sehingga para generasi muda tertarik untuk menggeluti sektor pertanian.

Disamping masalah SDM, pertanian di Indonesia juga dihadapkan pada problem berkurangnya luas lahan pertanian karena alih fungsi untuk perumahan dan industri. Luas lahan sawah pada tahun 2019 seluas 7,1 juta hektar, lahan sawah tersebut mengalami penyusutan dibandingkan tahun 2017 seluas 7,75 juta hektar (CNN, 2018). Akhir-akhir ini banyak dikembangkan urban farming untuk mengatasi sempitnya lahan pertanian. Urban farming merupakan suatu konsep dalam pemanfaatan lahan terbatas untuk kegiatan pertanian ataupun perkebunan. Urban farming dapat digunakan untuk memberdayakan masyarakat-masyarakat marginal di perkotaan dengan berbagai pendekatan yang dapat digunakan. United Nations Center for Regional Development (Trisyani et al., 2013) mengemukakan adanya tiga pengertian pembangunan masyarakat yaitu: (1) Pembangunan masyarakat sebagai pengadaaan pelayanan masyarakat, identik dengan peningkatan pelayanan sosial seperti fasilitas kesehatan, pendidikan, sanitasi, dan peningkatan gizi, dan lain-lain yang keseluruhannya bertujuan untuk meningkatkan kesejahteraan masyarakat; (2) Pembangunan masyarakat sebagai upaya terencana untuk mencapai tujuan nasional, seperti keadilan, pemerataan, culture promotion, dan kedamaian pikiran (peace of mind); (3) Pembangunan masyarakat sebagai upaya yang terencana demi meningkatkan kemampuan masyarakat untuk membangun. Paradigma yang digunakan adalah pembangunan berpusat pada manusia (people centered development).

Urban farming sendiri selain dapat diterapkan di lingkungan masyarakat perkotaan, juga dapat diterapkan di lingkungan sekolah di perkotaan dengan konsep School Garden. School Garden merupakan sebuah areal taman dalam sekolah yang dapat dijumpai dalam berbagai bentuk, ukuran dan tujuan (FAO, 2006). School Garden dapat terdiri dari beberapa jenis tanaman sayur, bunga, tanaman obat, tanaman keras, dan lainnya (FAO, 2006).

School Garden dapat diterapkan di berbagai sekolah untuk mencukupi kebutuhan gizi/nutrisi siswa siswi di sekolah tersebut, untuk memenuhi keperluan rumah tangga bagi stakeholder di sekolah tersebut dengan memanfaatkan hasil panen yang diperoleh di areal School Garden. Selain hasil panen yang dapat dimanfaatkan, areal School Garden diharapkan dapat menumbuhkan rasa cinta akan pertanian pada siswa siswi sekolah, sehingga sektor pertanian tidak ditinggalkan generasi muda, melainkan tetap dilirik untuk dikembangkan (Block et al., 2012). 
ABDIMAS: Jurnal Pengabdian Masyarakat Universitas Merdeka Malang Volume 6, No 2, May 2021: 534-540

Upaya meningkatkan rasa cinta terhadap pertanian dapat dimulai sedari dini di sekolah dengan konsep School Garden. Salah satu SD di Yogyakarta yang mempunyai potensi untuk kegiatan School Garden adalah SD Model Sleman, yang terletak di Wedomartani, Sleman, Yogyakarta. School Garden akan melibatkan stakeholder sekolah, dalam hal ini kepala sekolah, guru, dan siswa. SD Model merupakan salah satu sekolah unggulan di Kabupaten Sleman, menempati lahan seluas lima hektar. Pemilihan SD Model sebagai mitra pengabdian karena potensi yang dimiliki dan tersedianya lahan yang memungkinkan untuk diwujudkan School Garden.

Pada awal Maret 2020 masyarakat dihebohkan dengan adanya pandemi COVID-19 yang merubah kehidupan manusia, termasuk dunia pendidikan. Pembelajaran di sekolah juga mengalami perubahan dari tatap muka di kelas menjadi pembelajaran daring. Pembelajaran daring menuntut siswa di depan laptop atau gadget. Hal ini juga berlangsung lama bisa menimbulkan kejenuhan pada siswa. Adanya pembelajaran daring School Garden dapat memberikan dinamika pembelajaran selama pandemi COVID-19 karena siswa melakukan aktivitas di luar rumah tetapi masih dalam lingkungan rumah. Di samping belajar siswa juga dapat berolahraga melakukan aktivitas bercocok tanam.

Diharapkan melalui kegiatan School Garden yang dilakukan di SD Model dapat menjadi rintisan School Garden di sekolah-sekolah yang akan menumbuhkan minat generasi muda untuk mencintai pertanian sehingga dapat mendukung terwujudnya kedaulatan pangan di Indonesia.

\section{METODE}

Kegiatan pengabdian kepada masyarakat ini bertujuan untuk membantu mitra dalam mengatasi permasalahan yang dihadapi. Mitra dalam hal ini adalah SD Model Sleman, Wedomartani, Sleman, Yogyakarta, yang melibatkan siswa-siswi kelas 5A, 5B, dan 5C. Langkah-langkah pengabdian yang dilakukan untuk mencapai tujuan tersebut adalah sebagai berikut: (1) Melakukan diskusi dengan pengelola sekolah untuk mengetahui permasalahan yang dihadap. Berdasarkan hasil diskusi tersebut dapat diidentifikasi permasalahan-permasalahan yang dihadapi oleh sekolah dan merumuskan solusi terpilih; (2) Melakukan koordinasi dengan kepala sekolah dan guru untuk menentukan waktu dan areal pelaksanaan kegiatan serta metode pelaksanaan pengabdian. Adanya pandemi COVID-19 menyebabkan kegiatan pengabdian tidak dapat dilaksanakan di sekolah. Kegiatan pengabdian dilaksanakan secara mandiri oleh siswa dengan menggunakan panduan video tutorial dan modul yang diberikan kepada siswa; (3) Melaksanakan pengabdian dengan memberikan pengetahuan kepada siswa tentang jenis tanaman hortikultura yang difokuskan pada tanaman hortikultura dan urban farming serta arti penting pertanian bagi masa depan Indonesia. Kegiatan ini bertujuan untuk meningkatkan rasa cinta para siswa terhadap pertanian. Pada kegiatan ini juga dikenalkan mengenai penggunaan media tanam, pupuk kandang/organik, karena pupuk organik ini memiliki beberapa kelebihan dibandingkan dengan pupuk lainnya: (a) Memperbaiki tekstur tanah, (b) Meningkatkan pH tanah, (c) Menambah unsur makro \& mikro, (d) Meningkatkan keberadaan organisme dalam tanah, dan (e) Relatif tidak menimbulkan polusi bagi lingkungan (Nurwati et al., 2017). Kegiatan ini dilakukan oleh pengabdi melalui video tutorial dan modul. Video tutorial dapat diakses di https://youtu.be/BgoOjnIK1E8. 
Kemudian selanjutnya: (4) Melaksanakan pelatihan tentang cara bercocok tanam tanaman hortikultura. Kegiatan ini dimaksudkan agar para siswa mempunyai pengetahuan dan keterampilan dalam bercocok tanam tanaman hortikultura. Kegiatan ini dilakukan siswa secara mandiri di rumah dan dikompetisikan. Pada akhir kegiatan pengabdian dilakukan penilaian dan dipilih siswa yang berhasil melakukan budidaya tanaman dengan baik. Setiap kelas dipilih dua orang siswa dan mendapatkan apresiasi. Aktivitas siswa selama bercocok tanam di rumah didokumentasikan melalui foto/video tutorial tentang cara bercocok tanam tanaman hortikultura dapat diunduh siswa melalui https://youtu. be/BgoOjnIK1E8, disamping itu juga ada modul kegiatan; (5) Ketertarikan siswa terhadap kegiatan School Garden dan pertanian secara umum diukur menggunakan angket yang disebarkan kepada para siswa. Angket disebarkan menggunakan fasilitas Google Form; (6) Melakukan pendampingan. Kegiatan ini dilaksanakan untuk menjamin keberlangsungan program dan memastikan para siswa dapat melaksanakan kegiatan seperti yang telah direncanakan. Komunikasi dilakukan secara intensif sehingga dapat dipantau perkembangan kegiatan yang dilaksanakan oleh siswa secara mandiri.

\section{HASIL DAN PEMBAHASAN}

Kegiatan pengabdian kepada masyarakat tentang pengenalan School Garden yang dilaksanakan di SD Model Sleman telah dilaksanakan sejak bulan Mei-Juni 2020. Kegiatan ini semula direncanakan menggunakan lahan sekolah sebagai sarana pembelajaran bagi siswa untuk lebih mengenal teknik bercocok tanam sehingga menumbuhkan rasa cinta terhadap pertanian. Adanya pandemi COVID-19, tim pengabdi dan pengelola SD Model mencari alternatif pembelajaran, akhirnya disepakati pembelajaran dilakukan secara mandiri oleh siswa di rumah masing-masing. Untuk memudahkan para siswa dalam melaksanakan kegiatan tersebut dipandu menggunakan video tutorial, modul, dan konsultasi online melalui WhatsApp group. Karena tidak semua siswa mempunyai lahan untuk bercocok tanam maka pada kegiatan ini kepada para siswa dikenalkan konsep urban farming, bercocok tanam pada lahan terbatas menggunakan wadah/pot dari barang-barang bekas sampah rumah tangga. Penggunaan sampah rumah tangga sebagai pot seperti terlihat pada Gambar 1.

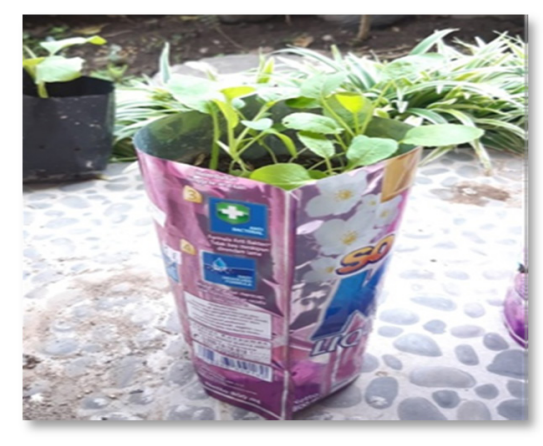

Gambar 1. Pemanfaatan sampah rumah tangga sebagai pot tanaman

Kegiatan pengabdian yang telah dilakukan ini menjadi salah satu alternatif pembelajaran pada era pandemi COVID-19, dimana pembelajaran dilakukan secara daring. Melalui pembelajaran School Garden 
ABDIMAS: Jurnal Pengabdian Masyarakat Universitas Merdeka Malang

Volume 6, No 2, May 2021: 534-540

ini dapat mengurangi kejenuhan siswa selama beberapa bulan di rumah, para siswa dapat melakukan aktivitas di luar rumah berinteraksi dengan alam sekitar namun masih dalam lingkungan rumah. Kesimpulan tersebut diambil berdasarkan angket yang disebarkan sebanyak 97,7\% siswa menyukai kegiatan pembelajaran School Garden yang mereka laksanakan secara mandiri di rumah, seperti dapat dilihat pada Gambar 2.

Hal tersebut juga didukung dengan data tentang keinginan para siswa untuk mencoba bercocok tanam pada tanaman lain. Pada kegiatan ini siswa mendapat bantuan bibit tanaman berupa bibit sawi umur dua minggu.
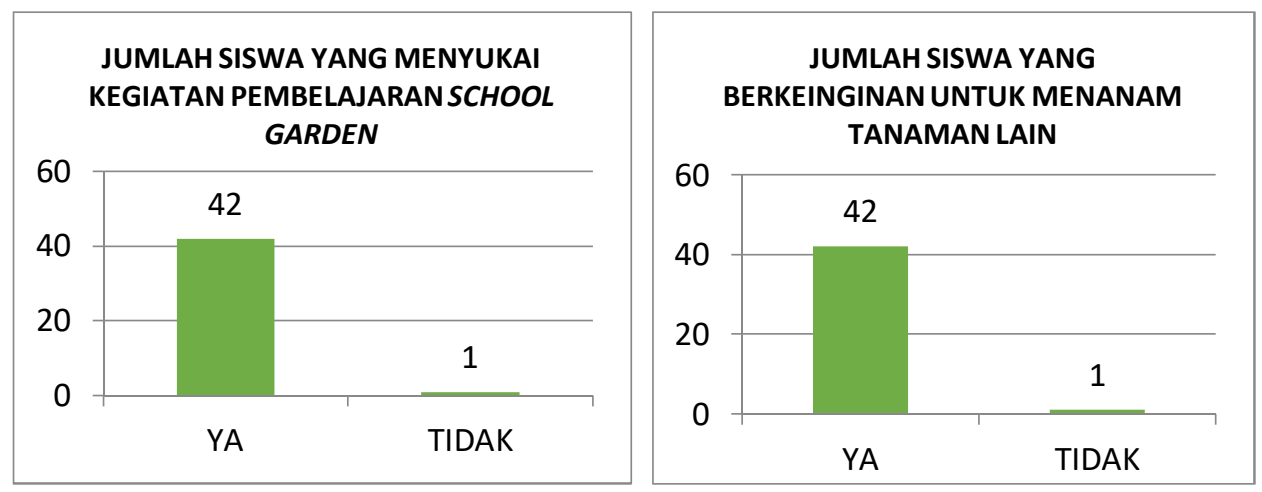

Gambar 2. Grafik jumlah siswa yang menyukai kegiatan pembelajaran School Garden Gambar 3. Jumlah siswa yang berkeinginan untuk menanam tanaman lain

Semua siswa sepakat kegiatan pembelajaran School Garden yang dilaksanakan secara mandiri bermanfaat meningkatkan pengetahuan dan keterampilan mereka.

Kegiatan pengabdian tentang pembelajaran School Garden yang dilaksanakan secara daring bermanfaat dapat menumbuhkan rasa cinta para siswa terhadap pertanian. Hal ini terbukti sebanyak $81,4 \%$ siswa menyatakan tertarik terhadap pertanian setelah melaksanakan kegiatan ini.
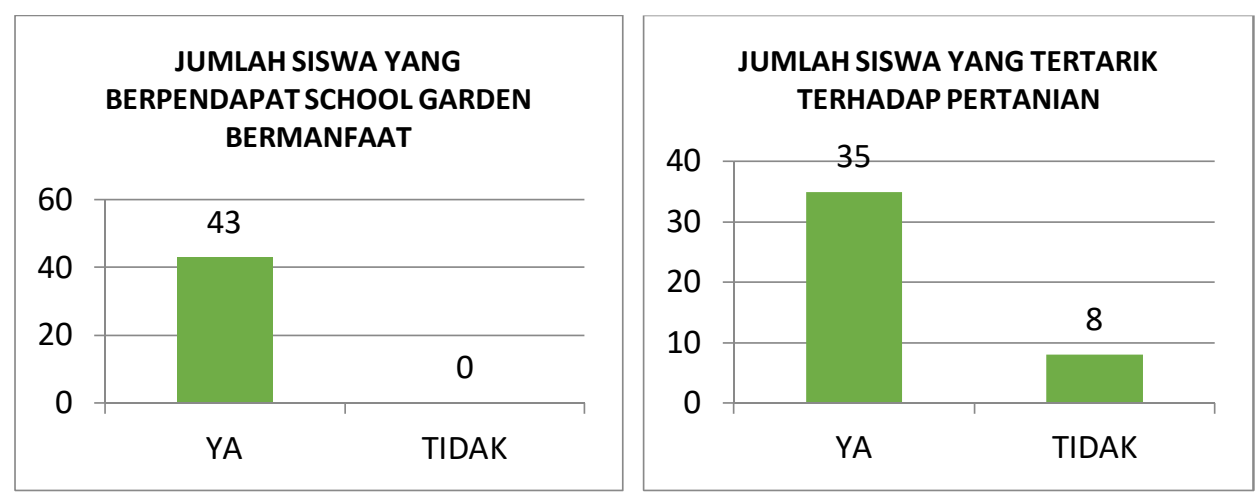

Gambar 4. Jumlah siswa yang berpendapat kegiatan pembelajaran School Garden bermanfaat meningkatkan pengetahuan dan keterampilan

Gambar 5. Jumlah siswa yang tertarik terhadap pertanian setelah melaksanakan pembelajaran School Garden 
Melalui kegiatan School Garden yang telah dilaksanakan bersama mitra SD Model Sleman, hasil yang diperoleh menunjukkan bahwa minat siswa-siswi cukup tinggi akan kegiatan budidaya pertanian, hal ini menunjukkan bahwa kegiatan tersebut mampu menumbuhkan minat generasi muda untuk mencintai kegiatan pertanian. Hal ini sesuai dengan penelitian dari (Ratcliffe et al., 2011), yang mengungkapkan bahwa pembelajaran School Garden memiliki dampak positif pada siswa-siswi, di antaranya adalah siswa-siswi mampu mengidentifikasi sayuran yang dibudidayakan di kebun, meningkatkan kreativitas dari siswa-siswi tersebut dan mampu mengidentifikasi berbagai sayuran yang ditanam di kebun rumah maupun sekolah.

Kegiatan School Garden juga mampu memberikan wawasan kepada siswa untuk lebih mengenal alam dan sebagai sarana promosi kesehatan agar siswa tertarik mengkonsumsi makanan sehat (Christodoulou \& K. Korfiatis, 2019; Lohr et al., 2019; Cairns, 2017). Penerapan School Garden juga dapat meningkatkan kesadaran agroekologi, nilai pengetahuan lokal, pengembangan nilai sosial di lingkungan sekolah dan kebiasaan konsumsi makanan (Ferguson et al., 2019; Swank \& Swank, 2013).

\section{SIMPULAN DAN SARAN}

Berdasarkan hasil dan pembahasan kegiatan pembelajaran School Garden pada era pandemi COVID-19 dapat disimpulkan bahwa siswa-siswa SD Model Sleman sebagian besar (97\%) menyukai kegiatan School Garden sebagai media alternatif pembelajaran, karena mampu meningkatkan pengetahuan, keterampilan, dan kreativitas siswa-siswi.

Berdasarkan evaluasi dari kegiatan pengabdian yang telah dilakukan, dapat diberikan saran untuk kegiatan selanjutnya ialah jika kondisi memungkinkan kegiatan School Garden dapat dilakukan secara offline di lingkungan sekolah dengan mempertimbangkan prokes (protokol kesehatan), pendampingan yang lebih intensif agar siswa-siswi dapat terampil dalam melakukan kegiatan budidaya pertanian secara mandiri baik di rumah maupun di lingkungan sekolah, pendampingan dapat dilakukan bukan hanya dari segi proses budidaya melainkan juga proses panen hingga pengolahannya.

\section{UCAPAN TERIMA KASIH}

Ucapan terimakasih disampaikan kepada LPPM UPY yang telah mendanai kegiatan pengabdian kepada masyarakat melalui Hibah Pengabdian Masyarakat. Ucapan terimakasih juga diberikan kepada kepala sekolah, guru, staf, dan murid-murid SD Model Sleman Daerah Istimewa Yogyakarta.

\section{DAFTAR PUSTAKA}

Block, K., Gibbs, L., Staiger, P. K., Gold, L., Johnson, B., Macfarlane, S., \& Townsend, M. (2012). Growing community: The impact of the Stephanie Alexander Kitchen Garden Program on the social and learning environment in primary schools. Health Education \& Behavior, 39(4), 419-432. https://doi.org/10.1177/1090198111422937 
ABDIMAS: Jurnal Pengabdian Masyarakat Universitas Merdeka Malang

Volume 6, No 2, May 2021: 534-540

Badan Pusat Statistik (BPS). (2019). Impor kedelai menurut negara asal utama 2010-2018. Badan Pusat Statistik. https://www.bps.go.id/statictable/2019/02/14/2015/impor-kedelai-menurutnegara-asal-utama-2010-2018.html

Cairns, K. (2017). Connecting to food: cultivating children in the School Garden. Children's Geographies, 15(3), 304-3018. http://dx.doi.org/10.1080/14733285.2016.1221058

Christodoulou, A., \& K. Korfiatis. (2019). Children's interest in School Garden projects, environmental motivation and intention to act: A case study from a primary school of Cyprus. Applied Environmental Education and Communication, 18(1), 2-12. https://doi.org/10.1080/1533015X.2017.1419104

CNN. (2018). BPS sebut luas lahan pertanian kian menurun. CNN Indonesia. https://www.cnnindonesia. com/ekonomi/20181025153705-92-341433/bps-sebut-luas-lahan-pertanian-kian-menurun

FAO. (2006). School Gardens. http://fao.org/schoolgarden/

Ferguson, B. ., Morales, H., Chung, K., \& Nigh, R. (2019). Scaling out agroecology from the School Garden: The importance of culture, food, and place. Agroecology and Sustainable Food Systems, 43(7), 724-743. https://doi.org/10.1080/21683565.2019.1591565

Lohr, A. ., Henry, N., Roe, D., Rodriguez, C., Romero, R., \& Ingram, M. (2019). Evaluation of the impact of School Garden exposure on youth outlook and behaviors toward vegetables in Southern Arizona. Journal of School Health, 90(7), 572-581. https://doi.org/10.1111/josh.12905

Nugroho, A. D., Waluyati, L. R., \& Jamhari, J. (2018). Upaya memikat generasi muda bekerja pada sektor pertanian di Daerah Istimewa Yogyakarta. JPPUMA: Jurnal Ilmu Pemerintahan dan Sosial Politik UMA (Journal of Governance and Political Social UMA), 6(1), 76-95. https://doi.org/10.31289/jppuma.v6i1.1252

Nurwati, N., Siswati, L., \& Mufti, M. (2017). Pelatihan pembuatan pupuk organik dari kotoran sapi di Kelurahan Tebing Tinggi Okura Kota Pekanbaru. Dinamisia: Jurnal Pengabdian Kepada Masyarakat, 1(1), 84-89. https://doi.org/10.31849/dinamisia.v1i1.424

Ratcliffe, M. M., Merrigan, K. a., Rogers, B. L., \& Goldberg, J. P. (2011). The effects of School Garden experiences on middle school-aged students' knowledge, attitudes, and behaviors associated with vegetable consumption. Health Promotion Practice, 12(1), 36-43. https://doi.org/10.1177/1524839909349182

Swank, J. M., \& Swank, D. E. (2013). Student growth within the school garden: Addressing personal/ social, academic, and career development. Journal of School Counseling, 11(21), n21.

Trisyani, N., Trisbiantoro, D., \& Madyowati, S. O. (2013). Model pemberdayaan masyarakat kawasan pesisir Kecamatan Watulimo, Kabupaten Trenggalek. LPPM Lembaga Penelitian Universitas Dr. Soetomo. 